\title{
The oxidative status and inflammatory level of the peripheral blood of rabbits infested with Psoroptes cuniculi
}

\author{
Xiaofei Shang ${ }^{1,2^{*}}$, Dongsheng Wang ${ }^{1,2}$, Xiaolou Miao ${ }^{1,2}$, Xuezhi Wang ${ }^{1,2^{*}}$, Jianxi Li $i^{1,2}$, Zhiqiang Yang ${ }^{1,2}$ \\ and Hu Pan ${ }^{1,2^{*}}$
}

\begin{abstract}
Background: Psoroptes cuniculi can parasitise the ear canal of the rabbit, and cause the afflicted animals to cease feeding and become severely debilitated, sometimes resulting in death. In this study, we examined the oxidative status and inflammatory level of the peripheral blood of rabbits infested with Psoroptes cuniculi and investigated the pathogenesis of this disease.

Methods: A total of 24 rabbits were divided into a healthy rabbit group and two infested rabbit groups. After weighing the rabbits, approximately $5 \mathrm{ml}$ of blood was obtained from each animal. Then, the blood serum was extracted and used to assess the levels of antioxidant enzymes and inflammatory factors.

Results: Compared to the healthy rabbits, the activities of catalase and glutathione-S-transferase and the level of malonyldialdehyde were increased, but the activity of superoxide dismutase was reduced in the infested rabbits. At the same time, a variety of inflammatory cells were activated, and the levels of inflammatory factors such as prostaglandin $E_{2}$, interleukin-6, interleukin-8 and transforming growth factor- $\beta 1$ were increased in peripheral blood.

Conclusion: Animal acariasis was associated with immunosuppressive disorders and inflammatory reaction. These results advance our understanding of the pathogenesis of Psoroptes cuniculi infestation in rabbits and can help guide the effectual treatment of this disease in clinics.
\end{abstract}

Keywords: Rabbits, Psoroptes cuniculi, Oxidative status, Superoxide dismutase, Inflammatory factor

\section{Background}

Animal acariasis is a veterinary skin disease that can reduce the productivity and the quality of animal products [1]. As a pathogen, Psoroptes parasitizes the body surface or the epidermis of sheep, horse, rabbit, goat, cattle and buffalo, etc., causing the afflicted animals to cease feeding and become severely debilitated. In rabbits, Psoroptes cuniculi can damage the pineal layer of the rabbit ear. Infestation can occur by direct contact with infested rabbits or by contact with infected bedding, especially for

\footnotetext{
* Correspondence: shangxf928@126.com; wangxuezhi@caas.cn; panhu@caas.cn ${ }^{1}$ Key Lab of New Animal Drug Project, Lanzhou 730050, Gansu Province, People's Republic of China

${ }^{2}$ Key Laboratory of Veterinary Pharmaceutical Development, Ministry of Agriculture, Lanzhou Institute of Husbandry and Pharmaceutical Sciences of Chinese Academy of Agricultural Science, Lanzhou 730050, People's Republic of China
}

young rabbits and peaked rabbits (Figure 1). If the infestation is not treated, it may cause serious economic loss due to decreased food consumption and the development of meningitis or the death of the animal [2]. It is therefore necessary to study the pathogenesis of this disease for developing the new drug or the therapeutic method.

Now, more and more scientific reports have focused attention on sarcoptic mange in animals, it is thought that the disease is associated with immunosuppressive disorders [3]. In addition, the immune status of the animal, the nutritional status and oxidative stress may play very important roles in the pathogenesis of this disease [4-7]. However, up to now, except for a study by Singh et al. that proposed that a significant alteration of the oxidant/antioxidant balance is a factor in the pathogenesis of 


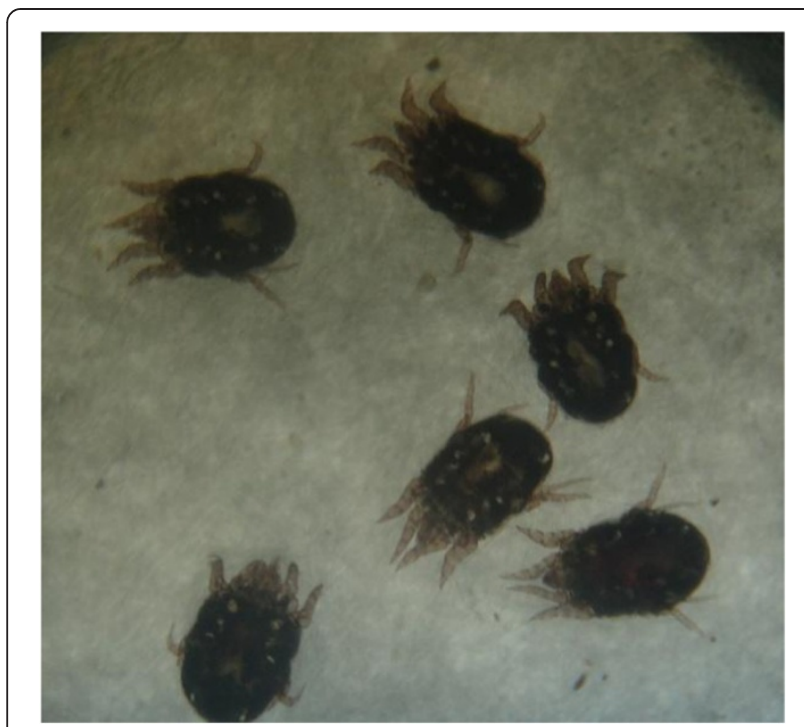

Figure 1 The picture of Psoroptes cuniculi under microscope (16*10).

P. cuniculi infestation of rabbits and that recovery could be enhanced by combining ivermectin treatment with vitamin $A, D_{3}$, E, and $H$ supplementation [8], no other studies have examined the oxidative status or levels of inflammatory factors in the peripheral blood of rabbits infested with P. cuniculi to our knowledge.

As we know, once animals are infested with Psoroptes cuniculi, they would and would induce an immune reaction by mites. Then, the oxidant/antioxidant balance in animals would be disturbed and some oxidative substances would be constantly generated in vivo, such as reactive oxygen species (ROS) [8,9]. When these substances generated overloaded the antioxidant defense, the free radicals could interact with endogenous macromolecules and alter the cellular functions, and induce some serious adverse effects on the skin, including edema, erythema, wrinkling, inflammation, autoimmune reaction, etc. $[10,11]$. At the same time, animals would develop the anti-oxidative mechanisms to minimize oxidative damage, some enzymes and anti-oxidant factors would be activated or released, such as glutathione peroxidase (GSH-Px), glutathione-S-transferase (GST), superoxide dismutase (SOD) [12]. However, how the oxidative status and inflammation levels change, and which antioxidant and inflammatory factors are activated or released are still unclear.

In this paper, we studied the oxidative status and inflammation levels of rabbits with psoroptic mange by determining the activities of the antioxidant enzymes and the levels of inflammatory factors in the peripheral blood. Our goal was to develop a better understanding of the pathogenesis of this disease.

\section{Methods}

\section{Experimental animals and groups}

Rabbits (80-100 days of age) were obtained from the Experimental Animal Center, Lanzhou Institute of Biologicals (Lanzhou, China). The experiments complied with the rulings of the Gansu Experimental Animal Center (Gansu, China) and were officially approved by the Ministry of Health, P.R. China in accordance with NIH guidelines.

In this study, all of the diseased rabbits were divided into two groups (scores of 3 and 6). Each group consisted of 8 rabbits, and 8 healthy rabbits were used as the healthy control group. They were kept in cages where they had free access to food and water, and they were maintained on a $12 \mathrm{~h}$ light/dark cycle.

\section{Selected rabbits}

The inclusion criteria for the animals selected for this study have been previously described by Fichi et al. and Shang et al. $[13,14]$. Briefly, before enrolment in the study, all of the rabbits were examined by clinical and dermatological methods with an otoscope and a microscope. The rabbits were naturally infested with Psoroptes cuniculi and suffered from the clinical disease for at least 10 days before presentation. None of the rabbits had been treated with ectoparasiticides or steroidal antiinflammatory drugs in the 30 days before the blood samples were drawn. The degree of infestation was evaluated according to a previously described scoring system: 0 indicated an absence of scabs and or mites; 0.5 was irritation in the ear canal but no mites observed; 1 was a small number of scabs in the ear canal, mites present; 2 was external ear canal filled with scabs, mites present; 3 was scabs in ear canal and proximal $1 / 4$ of the pinna, mites present; 4 was pinna half-filled with scabs, mites present; 5 was $3 / 4$ of the pinna filled with scabs, mites present; 6 was the entire internal surface of the pinna covered with scabs, mites present [9]. In this study, samples were collected from diseased animals with scores of 3 and 6 and from healthy animals with scores of 0 that were free of other diseases, as determined by laboratory and clinical examination. After the samples were collected, the rabbits were treated immediately.

\section{Weight and blood samples}

After careful laboratory and clinical examination, all of the rabbits were weighed. Then, $3 \%$ pentobarbital sodium $(30 \mathrm{mg} / \mathrm{kg})$ was used for the sedation of rabbits and approximately $5 \mathrm{ml}$ of blood was obtained from the auricular vein of each animal using a sterile needle into tubes. After standing for $30 \mathrm{~min}$, the serum was extracted from the blood samples and stored at $-20^{\circ} \mathrm{C}$ for up to 5 days. It was used to assay the oxidative stress and inflammatory factors promptly. 


\section{Assay for oxidative stress}

After collecting the blood serum, $100 \mu \mathrm{l}$ aliquots were used to determine the activities of superoxide dismutase (SOD), catalase (CAT), glutathione-S-transferase (GST) and malonyldialdehyde (MDA) with a Nanjing Jiancheng assay kit (Nanjing Jiancheng Bioengineering Institute, Jiangsu, China). Detailed, SOD activity in blood serum was measured by using nitro blue tetrazolium as a substrate after suitable dilution with SOD assay kit (Lot. 20130424), the increase in absorbance was scanned with an ultraviolet spectrophotometer (Evolution 300 UV-VIS, Thermo Scientific, U.S.A.) at $550 \mathrm{~nm}$. One unit of SOD activity was defined as the amount of enzyme that inhibited autooxidation by $50 \%$ under the given experimental condition and the values were expressed as $\mathrm{U} / \mathrm{ml}$. CAT activity in blood serum was estimated by using $\mathrm{H}_{2} \mathrm{O}_{2}$ as a substrate with CAT assay kit (Lot. 20130506), and the absorbance was scanned at $405 \mathrm{~nm}$ by ultraviolet spectrophotometer. GST activity was determined by assaying the concentration of GSH with GST assay kit (Lot. 20130528), and the absorbance was scanned at $412 \mathrm{~nm}$ by ultraviolet spectrophotometer. The concentration of MDA, a reliable marker of lipid peroxidation, was estimated in blood serum following the manual of Nanjing Jiancheng MDA assay kit (Lot. 20130407). Optical density was measured using an ultraviolet spectrophotometer at $532 \mathrm{~nm}$ against blanks prepared by using distilled water. The activities of SOD, CAT and GST and the level of MDA were calculated from the resulting absorbance values.

\section{Assay for inflammatory factors}

After collecting the blood serum, $10 \mu \mathrm{l}$ aliquots were used to determine the levels of prostaglandin $\mathrm{E}_{2}\left(\mathrm{PGE}_{2}\right)$, interleukin-6 (IL-6), interleukin-8 (IL-8) and transforming growth factor- $\beta 1$ (TGF- $\beta 1$ ) with rabbit ELISA PGE $_{2}$ assay kit, rabbit ELISA IL-6 assay kits, rabbit ELISA IL-8 assay kits and rabbit ELISA TGF- $\beta 1$ assay kits according to the manufacturer's instructions (R\&D System, U.S.A.), respectively. Briefly: firstly $10 \mu \mathrm{l}$ sample serum with $40 \mu \mathrm{l}$ sample diluents were added to 96-well plates (50 $\mu \mathrm{l}$ standard solutions). Following incubation for $30 \mathrm{~min}$ at $37^{\circ} \mathrm{C}$, the solutions were removed and the plate was washed 5 times with wash solution. $50 \mu \mathrm{l}$ HRP-conjugate reagents were then added to each well, and after incubating for $30 \mathrm{~min}$ for $37^{\circ} \mathrm{C}$ and washing 5 times again $50 \mu \mathrm{l}$ chromogen solutions $\mathrm{A}$ and $\mathrm{B}$ were added and incubated for $10 \mathrm{~min}$ at $37^{\circ} \mathrm{C}$ in the dark. Finally, $50 \mu$ of stop solution was added to each well, and the optical density was measured at $450 \mathrm{~nm}$ within 15 min using a microplate reader Multiskan MK3 (Thermo Scientific, U.S.A.), and the levels of $\mathrm{PGE}_{2}$, IL6 , IL- 8 and TGF- $\beta 1$ were calculated from the resulting absorbance values.

\section{Statistical analyses}

The data obtained were analyzed using SPSS software version 13.0 and expressed as the mean \pm SD. The data were analyzed by a one-way ANOVA followed by Student's two-tailed $t$-test for the comparison between test and control, and Dunnett's test was used when the data involved three or more groups. P-values of less than 0.05 $(P<0.05)$ were considered significant.

\section{Results \\ Weight of the rabbits}

We weighed all of the rabbits included in this study, which were selected for 80-100 days of age. The results showed that the healthy rabbits had an average weight of $2.15 \pm 0.410 \mathrm{~kg}$, and the weights of the rabbits infested with $P$. cuniculi with clinical scores of 6 and 3 were significantly decreased to $1.35 \pm 0.404 \mathrm{~kg}$ $(P<0.01)$ and $1.64 \pm 0.302 \mathrm{~kg}(P<0.05)$, respectively. This reduction in weight may be related to the oxidative stress and inflammation induced by the mites and if the degree of disease was more serious, the weight of rabbits was lighter.

\section{Assay for oxidative stress}

We determined the activities of three antioxidant enzymes. The results demonstrated that as an important metalloenzyme, the activity of SOD in the infested rabbits with clinical scores of $3(1.868 \pm 0.073 \mathrm{U} / \mathrm{ml})$ and 6 $(1.831 \pm 0.087 \mathrm{U} / \mathrm{ml})$ was weakly inhibited but not significantly different from that observed in the healthy rabbits $(1.918 \pm 0.061 \mathrm{U} / \mathrm{ml})$. However, the GST activity was significantly elevated in the infested rabbits with scores of $3(79.938 \pm 3.256 \mathrm{U} / \mathrm{ml})$ and $6(125.138 \pm 4.094$ $\mathrm{U} / \mathrm{ml})$ compared to the healthy controls $(67.783 \pm 3.694$ $\mathrm{U} / \mathrm{ml})(P<0.01)$. Meanwhile, the CAT activity in the infested rabbits with scores of $6(26.258 \pm 1.175 \mathrm{U} / \mathrm{ml})$ was increased compared to the healthy controls (21.335 \pm $1.135 \mathrm{U} / \mathrm{ml})(P<0.01)$. This was most likely due to the increased biosynthesis of the enzyme in response to $\mathrm{H}_{2} \mathrm{O}_{2}$ and other free radicals associated with $P$. cuniculi infestations. The MDA levels were assessed to evaluate the degree of lipid peroxidation in the body and to determine the potential role of lipid peroxidation in the pathogenesis of the infested rabbits. The result showed that the level of MDA in the infested rabbit with scores of $3(4.675 \pm$ $0.244 \mathrm{~nm} / \mathrm{ml})$ and $6(5.195 \pm 0.396 \mathrm{~nm} / \mathrm{ml})$ was markedly increased compared to the healthy rabbits $(2.835 \pm$ $0.180 \mathrm{~nm} / \mathrm{ml})(P<0.01)($ Table 1$)$.

\section{Assay for inflammatory factors}

Finally, we determined the level of four inflammatory factors in the peripheral blood of rabbits. The results demonstrated that compared to the healthy rabbits $(0.0880 \pm 0.0072 \mathrm{mg} / \mathrm{L}, 0.0198 \pm 0.0068 \mathrm{mg} / \mathrm{L})$, the levels 
Table 1 The activities of antioxidant enzymes (superoxide dismutase, catalase and glutathione-S-transferase) and the levels of malonyldialdehyde in the peripheral blood of infested rabbits and healthy rabbits

\begin{tabular}{llll}
\hline Oxidative factor & $\begin{array}{l}\text { Group A } \\
\text { (Healthy rabbits) }\end{array}$ & $\begin{array}{l}\text { Group B } \\
\text { (Infested rabbits with 3 score) }\end{array}$ & $\begin{array}{l}\text { Group C } \\
\text { (Infested rabbits with 6 score) }\end{array}$ \\
\hline SOD $(\mathrm{U} / \mathrm{ml})$ & $1.918 \pm 0.061$ & $1.868 \pm 0.073$ & $1.831 \pm 0.087$ \\
CAT $(\mathrm{U} / \mathrm{ml})$ & $21.335 \pm 1.135$ & $21.284 \pm 1.115$ & $26.258 \pm 1.175^{* *}$ \\
GST $(\mathrm{U} / \mathrm{ml})$ & $67.783 \pm 3.694$ & $79.938 \pm 3.256^{* *}$ & $125.138 \pm 4.094^{* *}$ \\
MDA $(\mathrm{nmol} / \mathrm{ml})$ & $2.835 \pm 0.180$ & $4.675 \pm 0.244^{* *}$ & $5.195 \pm 0.396^{* *}$ \\
\hline
\end{tabular}

${ }^{* *} P<0.01$ compared with control.

of the inflammatory factors IL- 6 and TGF- $\beta 1$ were markedly increased in the peripheral blood of the infested rabbits with scores of $3(0.1564 \pm 0.0074 \mathrm{mg} / \mathrm{L}, 0.0450 \pm$ $0.0061 \mathrm{mg} / \mathrm{L})$ and $6(0.2274 \pm 0.0118 \mathrm{mg} / \mathrm{L}, 0.1048 \pm$ $0.0341 \mathrm{mg} / \mathrm{L})(P<0.01)$. The levels of $\mathrm{PGE}_{2}$ and IL-8 were only significantly elevated in the infested rabbits with a score of $6(0.4612 \pm 0.0128 \mathrm{mg} / \mathrm{L}, 0.0554 \pm 0.0069 \mathrm{mg} / \mathrm{L})$ compared to the healthy controls $(0.2670 \pm 0.0131 \mathrm{mg} / \mathrm{L}$ and $0.0330 \pm 0.0083 \mathrm{mg} / \mathrm{L})(P<0.01)$ (Table 2).

\section{Discussion}

As a chronic skin disease, animal acariasis is induced by mites of Sarcoptidae and Psoroptidae when they were parasites in the surface or epidermis of animals. It can lead to acute pruritus and dermatitis of hosts [15]. Although rabbit ear mange begins as a topical disease, it can induce an inflammatory response and break the oxidant/antioxidant balance of animals as the illness progresses, even leading to systemic disease.

It is known that inflammatory cells are activated as a result of inflammation in animals with mange, and recruit neutrophils and macrophages with reactive oxidants, such as hydrogen peroxide $\left(\mathrm{H}_{2} \mathrm{O}_{2}\right)$, hypochlorite, and oxygen radicals. These reactive oxygen substances produced by cells of the immune system show potent cytotoxic effects on parasites and other pathogenic organisms [16]. Meanwhile, animals would develop the anti-oxidative systems to minimize oxidative damage by activating some enzymes and releasing anti-oxidant factors. In our study, when rabbits were infested with mites, the oxidative and anti-oxidative mechanisms were activated. The activities of CAT and GST in the peripheral blood were increased, and the activity of SOD was reduced compared to the healthy rabbits. Generally, changes in the activities of these antioxidant enzymes could break the oxidant/antioxidant balance in infested rabbits and exhaust the antioxidant system. Thus, this balance would shift towards oxidative stress. At the same time, as an indicator of oxidative stress in cells and tissue, the levels of MDA in the infested rabbits was markedly increased, and this is associated with the deterioration of cells, the development of skin lesions and the clinical manifestation of mange [17]. These results demonstrated that infestation stimulates oxidative stress, changes the antioxidant system and increases the level of lipid peroxidation throughout the body [16].

When the oxidant/antioxidant balance of animals is disrupted, overproductions of free radicals by the inflammatory cells are recruited to combat the parasites and consequent exhaustion of the antioxidant system of the infested rabbits. Meanwhile, a variety of inflammatory cells are activated, and this induces or activates various oxidant-generating enzymes to kill intra-cellular and extra-cellular parasites [18]. Subsequently, the inflammatory responses of the body are activated. In this process, components of the pro-inflammatory response to pathogens have been identified within circulating blood cells in hosts and these have been classified as the 'systemic inflammatory response', and some circulating

Table 2 The levels of inflammatory factors (prostaglandin $E_{2}$, interleukin-6, interleukin-8 and transforming growth factor- $\beta 1$ ) in the peripheral blood of infested rabbits and healthy rabbits

\begin{tabular}{llll}
\hline Inflammatory factor & $\begin{array}{l}\text { Group A } \\
\text { (Healthy rabbits) }\end{array}$ & $\begin{array}{l}\text { Group B } \\
\text { (Infested rabbits with 3 score) }\end{array}$ & $\begin{array}{l}\text { Group C } \\
\text { (Infested rabbits with 6 score) }\end{array}$ \\
\hline$P_{G}(\mathrm{mg} / \mathrm{L})$ & $0.2670 \pm 0.0131$ & $0.3000 \pm 0.0120$ & $0.4612 \pm 0.0128^{* *}$ \\
$\mathrm{IL}-6(\mathrm{mg} / \mathrm{L})$ & $0.0880 \pm 0.0072$ & $0.1564 \pm 0.0074^{* *}$ & $0.2274 \pm 0.0118^{* *}$ \\
$\mathrm{IL}-8(\mathrm{mg} / \mathrm{L})$ & $0.0330 \pm 0.0083$ & $0.0438 \pm 0.0056$ & $0.0554 \pm 0.0069^{* *}$ \\
$\mathrm{TGF}-\beta 1(\mathrm{mg} / \mathrm{L})$ & $0.0198 \pm 0.0068$ & $0.0450 \pm 0.0061^{* *}$ & $0.1048 \pm 0.0341^{* *}$ \\
\hline
\end{tabular}

${ }^{* *} P<0.01$ compared with control. 
leukocyte populations would present in the blood $[19,20]$. Meanwhile, the activity of circulating leukocytes contributes to the levels of cytokines and other proinflammatory markers, both systemically and at local sites of inflammation. As an important cell growth and regulatory factor, $\mathrm{PGE}_{2}$ plays a role in immunosuppression and anti-inflammatory effects. In our study, the levels of $\mathrm{PGE}_{2}$ of the infested rabbits were increased compared to the healthy rabbits. Meanwhile, as the important cytokines we observed that the levels of IL-6, IL- 8 and TGF- $\beta 1$ were increased compared to those in the healthy rabbits. These cytokines are released in response to the deterioration of cells and the development of skin lesions, together with the host-parasite interaction and immune-compromisation. Subsequently, the release of inflammatory factors or cytokines further activates the immune response, and excacerbates the disease. At the same time, the weight of the infested rabbits decreases as the animals became anorexic. If the infestation is not treated, it may cause serious loss, even death.

Now, more and more people are aware that animal acariasis induced by mites is not just the topical disease; but can also lead to some systemic disease, especially the oxidative response. In 2008 and 2012, Singh et al. and Kanbur et al. reported that after administrating vitamins as an adjunctive remedial to rabbits, the anti-oxidant activity and the recovery of the disease would be enhanced [8,17]. Then, Burgess et al. [21] thought that Psoroptes ovis would result in the host (sheep) systemic inflammatory response. In our study, the results indicated that psoroptic mange was associated with immunosuppressive disorders and inflammatory reaction, and the oxidant/antioxidant balance and the inflammatory factors of the rabbits infested with $P$. cuniculi were disrupted and released in the development of this disease, respectively. Based on the results, the administration of antioxidants, anti-inflammatory drugs or vitamins in conjunction with acaricides may improve the outcome of the disease. Similarly, treatment that is initiated at the early stage of the disease results in a better outcome.

\section{Conclusion}

In summary, the rabbits infested with $P$. cuniculi lost a dramatic amount of weight, demonstrated oxidative stress and released inflammatory factors into the peripheral blood. This caused extensive cellular damage throughout the body and resulted in compromised immune and inflammatory reactions. These processes may contribute to the pathogenesis of psoroptic mange.

\section{Competing interests}

All authors declare that they have no competing interests.

\section{Authors' contributions}

$\mathrm{XS}$ and DW conceived the study, XW and XM determined the index, XS, JL and $Z Y$ wrote the manuscript, HP performed statistical analyses. All the authors read and approved the final version of the manuscript.

\section{Acknowledgements}

This work was financed by the National Natural Science Foundation of China (31302136), the Special Fund for Agro-scientific Research in the Public Interest (201303040-14) and the Special Fund of the Chinese Central Government for Basic Scientific Research Operations in Commonwealth Research Institutes (No. 1610322014011).

Received: 17 January 2014 Accepted: 12 March 2014

Published: 25 March 2014

\section{References}

1. Dagleish MP, Ali Q, Powell RK, Butz D, Woodford MH: Fatal Sarcoptes scabiei infection of blue sheep (Pseudois nayaur) in Pakistan. J Wildl Dis 2007, 43:512-517.

2. Harkness JE, Wagner JE: Specific diseases and conditions. The Biology and Medicine of Rabbits and Rodents. USA: Williams \& Wilkins; 1995.

3. Patel JS, Patel RR, Panchasara HH, Brahamaxtri KG: Epizootiology of sarcoptic mange in buffalo calves. Indian Vet J 2003, 80:972-974.

4. Dimri U, Sharma MC, Swarup D, Ranjan R, Kataria M: Alterations in hepatic lipid peroxides and antioxidant profile in Indian water buffaloes from sarcoptic mange. Res Vet Sci 2008, 85:101-105.

5. Camkerten I, Sahin T, Borazan G, Gokcen A, Das A: Evaluation of blood oxidant/antioxidant balance in dogs with sarcoptic mange. Vet Parasitol 2009, 61:106-109.

6. De UK, Dey S: Evaluation of organ function and oxidant/antioxidant status in goats with sarcoptic mange. Trop Anim Health Prod 2010, 42(8):1663-1668.

7. Singh SK, Dimri U, Sharma MC, Swarup D, Sharma B: Determination of oxidative status and apoptosis in peripheral blood of dogs with sarcoptic mange. Vet Parasitol 2011, 178:330-338.

8. Singh SK, Dimri U, Sharma MC, Swarup D, Kumar M, Tiwary R: Psoroptes cuniculi induced oxidative imbalance in rabbits and its alleviation by using vitamins $A, D_{3}, E$, and $\mathrm{H}$ as adjunctive remedial. Trop Anim Health Prod 2012, 44:43-48.

9. Nemec A, Brobnic-Kosorok M, Skitek M, Pavlica Z, Galac S, Butinar J: Total antioxidant capacity (TAC) values and their correlation with individual antioxidants in serum of healthy beagles. Acta Vet Brno 2000, 69:297-303.

10. Muthukumaran S, Sudheer A, Menon VP, Nalini N: Protective effect of quercetin on nicotine-induced prooxidant and antioxidant imbalance and DNA damage in Wistar rats. Toxicol 2008, 243:207-215.

11. Bickers DR, Athar M: Oxidative stress in the pathogenesis of skin disease. J Invest Dermatol 2006, 126:2565-2575.

12. Halliwell B: Reactive species and antioxidants. Redox biology is a fundamental theme of aerobic life. Plant Physiol 2006, 141:312-322.

13. Fichi G, Flamini G, Giovanelli F, Otranto D, Perrucci S: Efficacy of an essential oil of Eugenia caryophyllata against Psoroptes cuniculi. Exp Parasitol 2007, 115:168-172.

14. Shang XF, Miao XL, Wang DS, Li JX, Wang XZ, Yan ZT, Wang CM, Wang Y, He XR, Pan H: Acaricidal activity of extracts from Adonis coerulea Maxim. against Psoroptes cuniculi in vitro and in vivo. Vet Parasitol 2013, 195:136-141.

15. Beijing Agriculture University: Parasitology of Domestic Animals. China: China Agriculture Press; 1981

16. Gurgoze SY, Sahin T, Sevgili M, Ozkutlu Z, Ozan ST: The effects of ivermectin or doramectin treatment on sone antioxidant enzymes and the level of lipid peroxidation in sheep with natural sarcoptic scap. Yuzuncu YII Universitesi Veteriner Fakultesi Dergisi 2003, 14:30-34.

17. Kanbur M, Atalay O, Ica A, Eraslan G, Cam Y: The curative and antioxidative efficiency of doramectin and doramectin + vitamin $A, D_{3}, E$ treatment on Psoroptes cuniculi infestation in rabbits. Res Vet Sci 2008, 85:291-293.

18. Kocyigit A, Keles H, Selek S, Guzel S, Celik H, Erel O: Increased DNA damage and oxidative stress in patients with cutaneous leishmaniasis. Mutat Res 2005, 585(1-2):71-78.

19. Huang Q, Liu D, Majewski P, Schulte LC, Korn JM: The plasticity of dendritic cell responses to pathogens and their components. Science 2001, 294:870-875. 
20. Politi FAS, Figueira GM, Araújo AM, Sampieri BR, Mathias MIC, Szabó MPJ, Bechara GH, Dos Santos LC, Vilegas W, Pietro RCLR: Acaricidal activity of ethanolic extract from aerial parts of Tagetes patula L. (Asteraceae) against larvae and engorged adult females of Rhipicephalus sanguineus (Latreille, 1806). Parasit Vect 2012, 5:295.

21. Burgess STG, Greer A, Frew D, Wells B, Marr EJ, Nisbet AJ, Huntley JF: Transcriptomic analysis of circulating leukocytes reveals novel aspects of the host systemic inflammatory response to sheep scab mites. Plos One 2012, 8:e42778.

doi:10.1186/1756-3305-7-124

Cite this article as: Shang et al:: The oxidative status and inflammatory

level of the peripheral blood of rabbits infested with Psoroptes cuniculi.

Parasites \& Vectors 2014 7:124.

\section{Submit your next manuscript to BioMed Central and take full advantage of:}

- Convenient online submission

- Thorough peer review

- No space constraints or color figure charges

- Immediate publication on acceptance

- Inclusion in PubMed, CAS, Scopus and Google Scholar

- Research which is freely available for redistribution 